\title{
Coming to Terms with History
}

\author{
Modernity and Agency
}

Tang Junyi pursued the highly ambitious goal of establishing a normative theory of modernity covering all spheres of society as well as the dimension of human subjectivity. This agenda is arguably a defining feature not only of Tang's philosophy, but also of mainstream Confucian thought since the 2oth century. An adequate appraisal of the Confucian philosophical projects must take into consideration their strong assumptions about Chinese and global history that permeate their attempts to reconstruct Confucianism. For Tang, there is no doubt "that the revival of Confucianism in a new form, i.e. a reconstruction of Confucianism is a necessary condition for keeping such a [historical] continuity in some East Asian countries." Apart from generating continuity, this reconstruction served another purpose, namely that of uncovering a broad range of social, cultural and political ideas, principles, values and norms that were to guide Chinese modernization.

Even though Tang never claimed that modernization as a whole could be guided by holistic social planning, he was convinced that modernizing communities could exert a considerable measure of control over the process of modernity. He believed that modernization on a global scale would, in the long run, lead to the establishment of modern nation-states with democratic and constitutional governments, and to pluralistic, industrialized and scientifically progressive societies (see Chap. 4). Modernity was thus not characterized by a forceful nature, as it was depicted, for example, in Max Weber's image of an "iron cage of dependence," which consists of the anonymous coercive power of bureaucratic and economic structures and processes that tend to subdue the individual and collectivities alike. Tang rejected such bleak prospects and claimed that modern man may retain the power of consciously choosing and opting for a specific type of modernity in terms of a project-a claim that pertains also to the reconstruction of Confucianism in the context of modernity:

1 Tang, "The Reconstruction of Confucianism and the Modernization of Asia," p. 361. 
... we have to acknowledge that there are some new ideas and new spirits which are missing in traditional Confucianism. If we do not want to keep Confucianism backward of age, we have to look forward and plan a reconstruction of the Confucian spirit to meet the modern need. ${ }^{2}$

Confucian concepts of modernization thus hold the promise that the project of modernity will produce an overall betterment of Chinese society and, eventually, also of non-Chinese societies. In this historical vision of modern Confucianism, the fact that China arrived belatedly to a modernizing world of nation-states does not take away the hope of "catching up" in terms of modernization. The notion of progress refers here to a willful collective effort that involves "learning" from historical experience, good or bad, Chinese or foreign. One striking example (among many) of this line of thought can be found in a passage where Tang elaborates on the economic backwardness of contemporary China. In a highly optimistic manner, he perceives this backwardness as a fortunate break that will provide China with an opportunity to avoid the consumerism and cultural-spiritual shallowness that has afflicted modernizing Western countries such as the United States, where, in the eyes of Tang, the reification of modern man was particularly severe. ${ }^{3}$

The expectation that China's project to catch up in terms of modernization is, essentially, manageable by a Chinese community whose members agree on the goals and means of modernization, is reminiscent of German theories of a "Sonderweg" (special path) in the modern world. Theories of a "Sonderweg," which emerged in Germany at the end of the 19th century, placed equal emphasis on belated efforts in nation building, industrialization and technological progress. Before the Second World War, these theories were applied in an affirmative manner, and centered on the assumption that there were actually many benefits to Germany's alleged ability to refute "Western" rationalism and adhere to its own superior cultural spirit. ${ }^{4}$ Tang's depiction of China's path to modernity and his project of a Confucian renewal is in line with the main thrust of theories of a Sonderweg that affirm cultural particularity. The core element here is the anticipation of a superior social modernity guided by humanistic values and ideas that are gleaned from a reinterpretation of

2 Ibid., p. 369.

3 Tang, Zhonghua renwen yu dangjin shijie, Vol. 8, p. 135.

4 For a concise introduction to theories of a German "Sonderweg," see Ottmann, Geschichte des politischen Denkens. Das 20. Jahrhundert. Der Totalitarismus und seine Überwindung, pp. $335^{-3} 38$. 
China's allegedly unique culture and history. On the basis of such reinterpretation, an effort to "learn" from achievements and failures in Western modernization shall take place.

The optimistic expectation of implementing modernization through a learning mode was widespread in 2oth-century China. ${ }^{5}$ Tang related the topic of "learning" not only to the sphere of collective action by the state and certain social agents, but even to how individuals conduct their lives. In a particularly striking statement from 1974, he mused about the "beautiful virtues" of the Chinese, which he said were still observable in the Taiwanese countryside. In contrast, he asserted that most city slickers in Taiwan and Hong Kong who indulged in materialistic lifestyles were under the negative influence of Western culture. The obvious conclusion was that "we just need the resolve to change customs, which will not be difficult [to do]," given that these negative customs came from "outside" and were thus not deep-rooted. If one really wanted to change them, it could be done right away. Tang provided a disturbing example of this by claiming that the CCP managed to rid Shanghai of lavishness and corruption after $1949 .{ }^{6}$ It seems that the point here was neither a vindication of communist measures to implement social change, nor a reaffirmation of the CCP's actions in Shanghai as a model for modernization. Still, Tang was obviously fascinated by the prospect of reining in the woes of modernization in such a willful collective effort.

The negative effects of the progressive division of labor in modern societies were treated in a similar manner. Tang pointed out that this is a crucial matter in Western countries, and particularly in the United States, because the increasing division of labor created a social situation in which individuals could no longer estimate the intrinsic value of their labor. ${ }^{7}$ The problem concerned not only the economic sphere but also such phenomena as the increasing "professionalization" in other social spheres, including academic life. These were signs of an ongoing submission of "cultural forces" to political and economic forces resulting in general tendencies of "reification" and cultural "degeneration." According to Tang, only purposeful change in the form of social and cultural activities might prevent these tendencies from spreading further into society. Such change was to include, as we have seen, a renewal of traditional Chinese associations on the level of communities. In these communal contexts, human

5 See Fröhlich, "Regulating, Governing, and Pacifying the Modern World: Optimism Regarding Progress in Chinese Interpretations of the Great Learning."

6 Tang, Zhonghua renwen yu dangjin shijie, Vol. 8, p. 324.

7 Ibid., p. 115 .

8 Tang, Zhonghua renwen yu dangjin shijie bubian, Vol. 10, p. 392. 
beings might truly interact with each other as individuals, and hence break up the uniform standards of instrumental values on the basis of their individualized value-consciousness. It is significant that Tang focused here on the form of these tradition-inspired associations and interactions, and not on specific contents and values.

In the same vein, he ascertained in very general terms that non-instrumental forms of interaction hinged on a revival of a "classical kind of spirit" in society, politics and ethics, which engendered a certain "value-consciousness." The individuals would learn to interact with each other by evaluating their respective accomplishments and knowledge within a broad range of intellectual or artistic activities as well as other forms of individual "effort" (gongfu). However, Tang did not naively believe that the workings of instrumental rationality might be completely dissolved in modern societies, but instead expected that they could be confined to their appropriate areas, such as the economic sphere. This might result in a foil for modern society in which the "lines of latitude," as Tang called them, could be calculated according to the "spirit of societies based on the division of labor of the modern type," and the "lines of longitude" according to a classical spirit. ${ }^{9}$ Tang seemed confident that East Asian societies, due to their particular cultural traditions, were in an excellent position to create these foils of social modernity. Yet, at that time, he identified Japan as the only country in the region to pursue such a course of modernization. ${ }^{10}$

To conclude, there can be no doubt that Tang deemed ideational factors to be crucial for solving global problems of modernity. He therefore highlighted an awareness of cultural traditions that should strengthen the consciousness of a "we"-group whose members are ready to act upon their normative choices.

Tang, Zhonghua renwen yu dangjin shijie, Vol. 8, pp. 115-118, 123, 125, 129. In this context, see also the following passage in which Tang rhetorically asks: "How can an individual spiritual being really be an individual, if his religious, moral, and cultural life is not integrated into a unity as a genuine Confucian aspires to?": Tang, "The Reconstruction of Confucianism and the Modernization of Asia," p. 365.

At times, Tang's confidence in the success of Japan's modernization was shattered, leaving him to express his hope that the Japanese would not define Japan's progress in industrialization solely in terms of an increase in industrial production alone, but also with respect to the benefits of cultural life; see Tang, Zhonghua renwen yu dangjin shijie, Vol. 8, p. 211. Whether Tang's topical way of thinking in longitudes and latitudes is inspired by topical thinking as prevalent in the philosophy of the Kyoto school is difficult to determine. Be that as it may, Tang obviously shared with the Kyoto school, and with influential European and American intellectual trends of the mid-2oth century, the apprehension that the process of modernity might entail strong tendencies of massification and deterioration of cultural standards. 
Such an endeavor, he believed, would involve a broad range of humanistic cultural activities, including intellectual, spiritual and aesthetic "efforts" of individuals to "overcome themselves," for example by engaging in Confucian scholarship, Chinese arts, Indian Yoga, Buddhism or Christian devotion."1

The main trajectory for propelling normative inputs in the course of modernization was, as Tang saw it, state action. Accordingly, he refrained from characterizing modernity as an increasing deterioration of the state's capacity to dominate societal development. On the contrary, the idea of an evolving modern Chinese state, still in the making, assumed an orienting function in the modern Confucian project. In spite of the misappropriation of state coercive power in the dictatorial party states in China before and after 1949, the idea of statehood still looms large in Tang's concept of modernization. Whereas he considered the extant party-states of the CCP and GMD to be bad options, he expected that the modern Chinese nation-state, in its democratic form, would evolve as an emanation from the normative resources of a renewed Confucian "main current."

In giving thought to the formation of the modern state, Tang drew selectively, as we have seen, from Hegel's concept of a state of ethical nature. But he was clearly not a Hegelian theoretician of state, and he accordingly refrained from applying the speculative framework of Hegelian philosophy of history to his own concept of state. As a consequence, he never referred to the historical manifestation of a "world spirit" in this context. Tang also differs from Hegel in that he envisioned the ideal form of the modern state as an immediate emanation of the human (ethical) will to the state. He thus designated the state to be the highest, direct manifestation of human reason in history (see Chap. 8 "State and Society") — and not, as Hegel would have it, as the historical manifestation of a "cunning of reason" which remains aloof from concerted human action. ${ }^{12}$ Tang bolsters his departure from the Hegelian theory of the state by criticizing Hegel for failing to clarify that the state, although it is a "manifestation of the objective spirit," cannot detach itself from the striving of "the subjective spirit which exists for itself," that is, a striving resulting "spontaneously" from the "rational self" and the moral will of individuals. ${ }^{13}$

The rejection of Hegelian speculation facilitated an optimistic vision of modernity: Given a successful "reconstruction" of the Confucian "main

11 Tang, Zhonghua renwen yu dangjin shijie, Vol. 8, pp. 56-57.

12 In the famous words of Hegel: "This may be called the cunning of reason-that it sets the passions to work for itself, while that which develops its existence through such impulsion pays the penalty, and suffers loss." Hegel, Philosophy of History, p. 47. 
current," China would be able to partake in global progress by implementing its own type of guided modernization. The general direction of this modernization would be foreseeable, because it was part of a global process of modernity that tended toward democracy and constitutional government, scientific and technological development, industrialization, and an open, pluralistic society. For Tang, modernity was thus not a lost cause for humanity, but carried, on the contrary, a promise to empower human agency to the point where it becomes the master of its own fate. The belief in such empowerment is indeed a salient feature of modern Confucianism. Pessimistic notions of modernity as an inescapable historical fate or as a process which is, essentially, beyond control fundamentally contradict the Confucian notion of human agency asserting itself in the process of modernization. Tellingly, Tang bluntly rejected, in his late work, Western notions of human history as an inevitably chaotic process characterized by contingent events, along with Western theories that undermine a firm belief in the effectiveness of "holy values," such as existentialism and the Freudian psychology of the unconscious. ${ }^{14}$ Even though he was apprehensive of human agency suffering from reification and alienation - a modern threat causing individuals to become oblivious to the dangers of modernity - he disagreed with an overall pessimistic vision of modernity. ${ }^{15}$

Tang's belief in the dominant role of human agency in the process of modernity is based on assumptions about human nature and the human being, which he obtained from his interpretations of Confucian thought. Two perspectives are particularly relevant in this regard:

1) Tang's civil theology asserts that the perfectibility of the human being as a sage is a historical reality, but such sagehood is neither a permanent state of mind nor an individual's way of life, nor can it be realized by whole collectivities of human agents, such as congregations, nations and classes. A revolution in the name of establishing a community of sages is consequently absent from Tang's modern Confucianism, as is the idea of a collective will totally dominating history. But the opposite notion is also absent, namely, the idea of human

\footnotetext{
14 Tang, Shengming cunzai yu xinling jingjie, Vol. 24, pp.461-462. Tang elucidated in this context the historical development of the "victory of Marxism" in China mostly in terms of a general loss of faith in "traditional" values of Chinese and Western cultures: ibid., p. 464. His skepticism towards existentialism dates back to at least the late 1950s; see his criticism of existentialism's inability to "actively" seek a solution for humanity's spiritual crises in the modern world: Tang, Zhonghua renwen yu dangjin shijie, Vol. 8, p. 57.

15 See for example Tang, Zhonghua renwen yu dangjin shijie, Vol. 8, p. 127.
} 
beings subdued by the process of modernity. ${ }^{16}$ In fact, Tang depicted "inner sagehood" as the moment in which the human mind breaks free from its own embedment in history. Accordingly, he conceived of the sage as being detached from a particular historical context. It is therefore no coincidence that nowhere in the modern Confucian discourses do we find the assumption that the very mode of an ahistorical, immediate presentification of sagehood itself changes under different historical circumstances. And whereas the so-called outer king (wai wang) is said to be in need of a "renewal" (xin), the "inner sage" (nei sheng) remains untouched by changing times. Obviously, by relating the notion of human nature to "inner sagehood," modern Confucianism presumes that human nature, and consequently the human being, is intangible vis-à-vis history, including the process of modernity. This, in turn, is the religiousanthropological basis for the Confucian insistence on the stronghold of human agency in history, including the process of modernity.

2) Modern Confucianism clearly refrains from claiming that human beings are perfectible as a species. Even if one was to believe that, at one point in history, a community of sages might be realized, their offspring would not be born as sages, nor would the institutions and structures of such a community perforce lead every human being to perfection. The perfectibility of the human being evidently pertains to the individual, not to the species, and as individuals human beings retain the freedom to strive for sagehood, or not to strive for it, or to strive and fail along the way. As a consequence, there will be no "end" of history brought about as the victory of sagely inwardness over all "outer," alienated formations of modernity. Tang's philosophy does not offer the consolation of an idyllic modern world that is free from alienation. But even though "objective" constellations of alienation will persist, the Confucian individuals may be spared the distress of experiencing them solely as "outer" obstacles. Instead, they can mitigate the downside of modernity as historical conditions

16 As mentioned above, Thomas Metzger subsumes Tang Junyi's modern Confucianism to the category of an "epistemological optimism" that is characterized by the assumption that the "ultimate reality" of all phenomena is detectable and describable by human beings; see Metzger, A Cloud across the Pacific. Essays on the Clash between Chinese and Western Political Theories Today, pp. 21-31, 171-182 [endnote 138], 220, 672-676. Yet with respect to Tang's philosophy, it should be noted that the idea of the human being's insight into the absolute truth of the "Heavenly principles" cannot be detached from the assumption that such an insight is attainable only in an ephemeral moment of intuition and only by individuals, never by whole (political) collectivities. As a consequence, the intuitive insight never amounts to a permanent, political state of existence. Claims to absolute truth, together with their totalitarian repercussions, are therefore not supported by Tang's political thought. 
of their quest for sagely inwardness, which might be attained in the course of participating in and struggling with the modern world.

The religious-anthropological notion of the intangibility of human nature marks one of the main rifts between modern Confucianism and Marxism. While both tend to emphasize the importance of the role of human agency with respect to the course of history, Marxism does so by positing that the human being should be considered the product of a historical and social formation. A purposeful transformation of human collectivities through generating the conditions for the emergence of a "new man" within a perfected society is feasible according to the Marxist scheme. In contrast, modern Confucianism assumes that the "nature" (xing) of the human being is not subject to historical change and remains essentially out of reach of any attempt to objectify or manipulate it. What is subject to change is indeed not the human being itself, but only its symbolic representations, which might find their "true" cultural expression in the humanistic "main current." This Confucian outlook had to be defended not only against Marxism, but also against positivist theories of historical research. Tang criticized these theories because he believed they reduced history to a mere "object" of research, and implied, at the same time, the depletion of subjectivity by stripping the human subject of its historical dimensions, thereby reducing it to a putatively pure subject of cognition. ${ }^{17}$

\section{History and Normativity}

Tang Junyi's speculation about history defies a clear-cut classification as philosophy of history, theology of history or philosophic-historical anthropology. The difficulties of classification partially stem from the fact that Tang was not a historian, neither by professional training nor by the thrust of his work. He himself referred to his speculation as a "philosophy of history" (lishi zhexue), yet this may lead, if taken at face value, to considerable misunderstandings. ${ }^{18}$

17 On Tang's criticism of positivism in the context of historical research, see for example: Tang, Zhonghua renwen yu dangjin shijie, Vol. 7, pp. 165, 167; for a discussion of this issue see Chap. 4 "Defending Authenticity."

18 The fact that Tang conceived of lishi zhexue not simply as a philosophy of history in the European tradition becomes evident when he agreed with Mou Zongsan that the Spring and Autumn Annals (Chunqiu 春秋) are the pioneering works of Chinese "lishi zhexue;" see Tang's article "A Philosophical Inquiry of Chinese History," published in the journal Rensheng (No. 120; November 1955): Tang, Zhonghua renwen yu dangjin shijie, Vol. 7, p. 178. Besides, Tang labeled the works of Ouyang Xiu 歐陽修 (1007-1072) and Sima Guang 司馬光 (1019-1086) as the beginning of “historical studies" (shixue 史學) in China and 
Instead of regarding Tang's "philosophy of history" as an offshoot of European philosophies of history, it is more apt to delineate it in a much broader conceptual framework - so broad that it even includes references to German historicism from the 19th century. The latter was indeed highly critical of classical European philosophies of history. It evolved in the political context of German nation-state building and was, in fact, a hotbed of the above-mentioned theories about a German "Sonderweg," while at the same time fostering the institutionalization of a professionalized science of history in modernizing German universities. Even though historicism was not, as its label seems to indicate, a historiographical school in the narrow sense of the word, the majority of classical historicist thinkers like Leopold von Ranke (1795-1886), Johann Gustav Droysen (1808-1884) and Wilhelm Dilthey (1833-1911) shared a profound skepticism towards philosophies of history as well as positivist approaches to historical research. ${ }^{19}$

Whether Tang's historical thinking was actually informed by German historicism is difficult to determine. His diaries reveal that he was reading a "book by Dilthey" in July 1953, but there is no title indicated..$^{20}$ There are other channels through which he might have become familiar with historicism, for example through the work of Chinese historians like Chen Yinke, whose concept of historiography suggests remarkable affinities to the basic tenets of historicism. Nevertheless, it remains unclear whether Chen and Tang actually had studied European historicist thought. ${ }^{21}$ Be that as it may, key historicist ideas appear repeatedly in Tang's own speculations about history. Among these is the assumption that the different periods in Chinese history need to be considered with respect to their particularity and uniqueness, for they each have, according to Tang, their own specific meaning and "value."22 Also in accordance with historicist thinkers, among them Ernst Troeltsch (1865-1923) and Dilthey, is the strong rejection of positivist claims to the objectivity of historical "facts," and the assertion that the quest for the meaning of history is inevitably bound

compared this achievement to the contributions of Galileo and Newton to Western science. Huang, Xueshu yu jingshi-Tang Junyi de lishi zhexue ji qi zhongji guanhuai, p. 25. But for all this praise, Tang still remained elusive about the actual innovations made by those scholars from the Song Dynasty.

19 See Iggers, Geschichtswissenschaft im 20. Jahrhundert, pp. 18-23.

$20 \quad$ Tang, Riji, Vol. 27, pp. 151-152.

21 On Chen Yinke's affinity to historicism, see Schneider, Wahrheit und Geschichte. Zwei chinesische Historiker auf der Suche nach einer modernen Identität für China, pp. 140-141. Tang, "Zhongguo wenhua zhi yuanshi jingshen ji suo jingli zhi tiaozhan yu you huiying er xingcheng zhi fazhan," p. 10. In contrast to most European historicist thinkers, Tang did not relate this uniqueness to the idea of equality before god. 
to the ascription of meaning to singular facts, events and intentional acts by individual interpreters:

This, then, [means that] with respect to identical historical facts, their meaning can originally contain interpretations added by men according to different orientations. As stated above, all of these interpretations are something that men have perceived and created. In these [interpretations], the historical facts themselves, which exist at the basic level, cannot necessarily determine [the following, namely]: the direction men's interpretations take at the higher level [of interpretation]. ${ }^{23}$

Instead of proclaiming the search for a universal truth in history as the foremost task of the interpreter, Tang underscored the pragmatic aspects of historical thought, and especially its function to provide normative orientation with regard to the present situation, ${ }^{24}$ i.e. the epochal interest in nation-building and the formation of a nation-state. In contrast, "positivist" historical thought appears to be restrictive because it disregards the present historical context and pretends to be completely detached from human praxis in society, politics, culture and ethics. ${ }^{25}$

In his rejection of positivism, Tang shared with Dilthey, Chen Yinke and others the hermeneutic awareness that interpreters of history should reflect not only on the context of their interpretations, but also on the formation of their own subjectivity. The latter comprises the moral personality of the interpreter, as well as everything that "makes up [his or her] personhood." As a consequence, the interpreter's moral standards are relevant to the interpretation. However, Tang assumed that the historical situation in which the interpreter exists does not predetermine the details of the interpretations, but only their general orientation, which includes the guiding ideas of the interpretations and the selection of historical sources. Therefore the values that the interpreter applies to history have only relative validity. Tang did not advocate a devaluation of the past by subsuming it to values and standards of the present. He rather expected, in line with historicism, that the engagement with the past as a foreign intellectual territory would produce new insights for the presentprovided that the approach to the past was one of "empathic understanding"

23 See Tang's article "Historical Facts and Historical Meaning," published in two consecutive issues of Minzhu Pinglun (Vol. 14, Nos. 22, 23; November 1963): Tang, Zhonghua renwen yu dangjin shijie, Vol. 7, pp. 165-166.

24 Tang, Zhonghua renwen yu dangjin shijie, Vol. 7, pp. 167-169.

25 Ibid., pp. 164, 166, 170. 
and "openhearted and upright intentions," which lead the interpreters to see themselves from a foreign perspective. ${ }^{26}$

One of the focal points of this hermeneutical engagement with history was to acquire a better understanding of the human being itself. What was at stake is the self-enlightenment of the interpreters about the true nature and constitution of human beings and their manifold cultural and social expressions. This orientation inspired Tang to inscribe the effort of interpreting history into the broad agenda of individual self-cultivation. ${ }^{27}$ Historical interpretations were to contribute to the individual's understanding of the nature of man. To this end, the intentions of human agents in history had to be reconstructed. Whether it is the history of the humanistic "main current," the demise of the Chinese nation since the mid-19th century, or China's democratic failures of the 2oth century, Tang's interpretations underscore the crucial impact of intentions, foresights or misapprehensions on the part of political, social and intellectual agents. Here, the traditional topic of history providing ethical education reappeared. The adherence to this well-known aspect of historiography in pre-modern China entailed the assertion that the interpreters of history may attain ethical insights by studying historical paragons whose acts can be judged as either good or bad. At the same time, the interpreters are said to produce "new meaning" in writing history, which in turn has an impact on the course of history itself. Yet Tang did not take these ideas to indicate that the "moral consciousness" itself was the product of a historical formation. ${ }^{28}$

26 Ibid., pp. 164-166.

27 Cheng Chung-yi concludes that Tang's hidden agenda of reconstructing a taxonomy of scholarship was one of guiding the human being's practical efforts to attain an authentic existence. In this context, Tang proposed a sequence of modern disciplines which he tried to bring into accord with the standard fourfold classification used in imperial libraries, which distinguished between "classics" (jing 經), "histories" (shi 史), "masters [philosophers]” ( $z i$ 子), and “collections [of literature]” ( $j i$ 集). Yet Tang's reconstruction seems to be forced and somewhat self-contradictory. He categorized, for example, "philosophy" as "zi," and as "jing" (which includes works of moral philosophy). He left, however, no doubt that "shi," which would include modern historical research, is closely linked to the individual's self-cultivating quest for authenticity; see Zheng (Cheng Chung-yi), “Tang Junyi lun renwen xueshu," pp. 362-363.

28 Tang, Zhonghua renwen yu dangjin shijie, Vol. 7, pp. 167-169. Tang related the notion of creating "new meaning" and therein acting as a "creator" of history to the Confucian notion of "transmitting the way" (dao tong 道統). He then referred to Confucius as the founding figure of historical speculation and took up the traditional belief that Confucius authored the Spring and Autumn Annals; see ibid., pp. 164, 168, 170. 
It is because of such proximity to historicism that Tang's lishi zhexue is clearly set apart from Hegelian philosophy of history. Overall, lishi zhexue is not an enterprise of detecting the self-realization of reason in history, as Hegel's philosophy of history claimed to do by retracing the historical manifestations of the "world spirit." The cosmic unity, i.e. the "mind of Heaven," does not permeate human history as a historical force. Consequently, Tang's speculation entails no idea of a world spirit present in history, ${ }^{29}$ and, what is more, he criticized Hegel's philosophy of history for its assumption that "all cultural affairs and heroic personalities" were mere vehicles for the self-manifestation of "absolute spirit." Hegel, it would thus seem, failed to acknowledge that the human being could indeed firmly establish its cultural activities and its individual personality as its own "inherent goals." ${ }^{30}$ In contrast to Hegelian philosophy of history, Tang measured historical reality against the religiousanthropological assumption that human beings are destined to realize their natural ability to attain sagehood. Tang's speculation about history is indeed intimately related to his Confucian civil theology. "Reason" in history is hence to be found in the formation of conditions which are conducive to individual self-perfection in sagehood-a formation that entails, to be sure, a dialectical structure, as Tang's analysis of the will for power had shown.

Tang's modern Confucianism conveys an overall optimistic outlook by depicting the course of history as pointing to an increasing formation of political, social and cultural conditions that are favorable to individuals' selfperfection. This optimism also pertains, as we have seen, to the process of modernity. Tang in fact left no doubt that modernization would amount to a betterment of individual and collective life - provided the members of the Chinese nation obtain an "authentic" understanding of the humanistic "main current." Chinese humanism hence appeared to have the capacity to rein in the woes of modernity:

What we are awaiting is merely the self-consciousness of all humanity, in which it will seek a common goal and then take up common endeavors. As for this common goal, one can talk about it from two perspectives: 1) It is indispensable to liberate "culture" from the heavy pressure of "politics" and "economics" and to do the utmost to have the "cultural powers" surpass the "political powers" as well as the "economic powers" (this is

29 See also Huang, Xueshu yu jingshi-Tang Junyi de lishi zhexue ji qi zhongji guanhuai, pp. $27,54-55,61-62$.

Tang, Zhongguo wenhua zhi jingshen jiazhi, p. 231. 
"humanism"). 2) Whatever the new social ideal is, those who make a great effort to realize this ideal must, at the same time, engage in self-reflection and clearly recognize in advance the potential abuses so as to prevent them in time (here, we must wait for those of great insight and wisdom). ${ }^{31}$

Yet this optimistic outlook gave rise to the problem of identifying foundational elements of necessity in history. Otherwise, what reason was there to be optimistic in the first place? Huang Zhaoqiang assumes that an "optimistic mind" was entrenched in Tang's conviction that the moral consciousness might overcome all hindrances in history and that this very conviction was, on top of it, a crucial impetus of historical betterment. According to Huang, Tang indeed believed that a moment of necessity was at work here. ${ }^{32}$ Stringent as this interpretation by Huang is, it probably underestimates the ambivalence in Tang's speculation with respect to the belief in a victory of morality in history. While Tang was convinced that the moral will might be able, in principle, to conquer historical reality, he stated time and again that it regularly failed for reasons that pertain to the finiteness, i.e. the inextricable moral imperfection, of the human being and its historical world.

Tang's difficulties with the problem of necessity are symptomatic of his trouble in coining a full-fledged Confucian philosophy of history. The fundamental reason for this trouble has to do with the unresolved and probably unresolvable tension between the attempt to historicize our understanding of the world, on the one hand, and the insistence on the Confucian religious-anthropological outlook that posits an unchanging, ahistorical and pre-determined "nature" of the human being, on the other. It is this outlook that accommodates the historicizing perspective, and not the other way around. This does not preclude historical-philosophical reflections, but the dominant perspective throughout is characterized by the attempt to relate history to the "natural" disposition of the human being, albeit in dialectical twists and turns.

Tang's strategy for dealing with the philosophical problem of historical necessity was one of avoidance. As an upshot, his optimism seems to be suspended in ambiguity, and resembles more a personal attitude or faith than a conviction based on stringent arguments. He asserted, for example, that the ideal of national unity of China would "necessarily" come about because the "historical impetus" (lishi dongli 歷史動力) of national and cultural life in

31 Tang, Zhonghua renwen yu dangjin shijie bubian, Vol. 10, p. 393.

32 See Huang, Xueshu yujingshi-Tang Junyi de lishi zhexue ji qi zhongji guanhuai, p. 132. 
China originated from a single root. ${ }^{33}$ "Ideals" entailed an "impetus" that "perforce" worked for their realization, and the truth of this could be revealed, as Tang maintained, by "philosophical reflection., ${ }^{34}$ The problem of coming to terms with the notion of historical necessity still looms large here, even more so since Tang himself remained skeptical with respect to the belief that ideals could actually forge history. He did not, after all, naively believe that history was guided by ideals or that ideals could be realized with ease. Besides, according to Tang, it was often impossible to identify those who were responsible for the failure to realize certain ideals. He even warned that attempts to implement ideals might lead to unintended negative effects. Any "consciousness" of ideals should therefore entail the awareness that ideals can produce negative results in historical reality. 35

Overall, Tang's dealings with this issue remain obscure. He elucidated neither the workings of necessity in depth, nor how the interpreter of history might detect or retrace the historical effects of necessity. Tellingly, whenever he referred to certain periods in Chinese or world history, he refrained from depicting the transformations of one period into the following as a necessary development involving specific antinomies as the driving forces of the transformation. ${ }^{36}$ There is, indeed, no clear-cut, comprehensive concept of distinct antinomies in Tang's "philosophy of history," which thus lacks a pivotal element of philosophies of history in the tradition of German idealist thought. ${ }^{37}$ The closest Tang came to positing a historical constellation of epochal antinomy was his reflection about the formation of modern Confucianism itself. The whole body of his work on the reconstruction and renewal of China's humanistic culture seems to suggest that modern Confucianism has arisen from inner contradictions of late imperial Chinese society, most of all related to problems of stabilizing the political and social order, and from the challenge of facing

33 Tang, "Zhongguo wenhua zhi yuanshi jingshen ji suo jingli zhi tiaozhan yu you huiying er xingcheng zhi fazhan," p. 10. For similar assumptions about quasi-necessary historical tendencies, see, for example, the assumption in the manifesto of 1958 about the "inner" trend in Chinese history towards the establishment of a constitutional democracy: Zhang, Zhongguo wenhua yu shijie, pp. 37-39.

34 Tang, Shengming cunzaiyu xinling jingjie, Vol. 24, p. 493.

35 Tang, Zhonghua renwen yu dangjin shijie bubian, Vol. 10, pp. 386, 388.

36 According to Tang, the different historical periods in Chinese history each have their own characteristics, meaning and value, and variously express the historical impetus of China's national and cultural life: Tang, "Zhongguo wenhua zhi yuanshi jingshen ji suo jingli zhi tiaozhan yu you huiying er xingcheng zhi fazhan," p. 10.

Odo Marquard assumes that the notion of distinct antinomies is a key element of philosophies of history; see Marquard, Schwierigkeiten mit der Geschichtsphilosophie, pp. 114-115. 
Western nation-states and Western thought. But it is not entirely clear whether Tang believed that the formation of modern Confucianism really entailed a moment of historical necessity. So even if he shared with classical European philosophies of history the basic assumption that history is evolving as "progress," he refrained from explicitly retracing the course of history by referring to the idea of a necessarily progressive advancement. He consequently did not seek factual proof for an unfolding of progress across the different historical periods.

\section{Signs of Progress}

In the face of the pending ambiguity of historical necessity, it seems that Tang contented himself with the idea that there are at least scattered signs or indicators of progress in history, which the interpreter can detect. These signs may be taken as pointing to a general tendency of historical progress towards a betterment of humanity and its societies. The fact that humanistic personalities time and again found a following and were able to shape the history of nations, peoples or states thus appeared as a sign of progress. The list of such figures mentioned by Tang in a variety of writings includes Confucius, Buddha, Jesus, Gandhi, but also Sun Yat-sen and Karl Marx. ${ }^{38}$ There is a distinct tendency in Tang's thought to elevate historical figures to a position of admiration, thereby underscoring the historical relevance of human agency in general. For example, when praising the "classical kind of spirit" that he deemed to be beneficial to modernizing societies, Tang highlighted the "classical" admiration of "great personalities" in politics, religion, culture and society in China and the West. ${ }^{39}$ In the same vein, he considered the persistent recurrence of the "classical" humanistic spirit itself to be an indication for progress in history, even though it did not necessarily emerge in a straight, unbroken line. Tang saw "humanity" rather following a "line winding upwards," one that is "in accordance with reason," but can be recognized only after history has taken its course. ${ }^{40}$ He hence

38 Such references to Confucius, Buddha and Jesus are abundant in Tang's writings; see for example Tang, Zhonghua renwen yu dangjin shijie bubian, Vol. 10, p. 442. For the reference to Gandhi, Sun Yat-sen and Marx see an article from 1952, quoted in Huang, Xueshu yu jingshi-Tang Junyi de lishi zhexue ji qi zhongji guanhuai, p. 142.

39 Tang, Zhonghua renwen yu dangjin shijie, Vol. 8, pp. 125-126.

40 Tang, Wenhua yishi yu daode lixing, p. 302. Tang argued here in accordance with Hegel's famous reflection on history at the end of his preface to the Philosophy of Right: "History thus corroborates the teaching of the conception that only in the maturity of reality does 
contradicted those theoreticians of history whom he presumed to be believers in a straight line of historical progress, like Marx, Condorcet, Comte and Spencer. ${ }^{41}$

In contrast to these concepts of linear, continuous progress in history, Kant's consideration on "signs of history" in his The Contest of Faculties $(1798)^{42}$ is partially in line with Tang's historical thinking. Kant dedicated the second section of his book to the question of whether humanity is on a course of constant progress and betterment-in the words of Kant, "Is the human race continually improving?" In order to answer this question, Kant introduced the idea of signs of history, which he believed serve to indicate a general tendency in human history, albeit not in the sense of a prognostic tool that provides the basis for specific forecasts about the future course of history. ${ }^{43}$ Like Tang, Kant did not claim to make propositions about the "betterment" of humanity as a species, but instead focused on human collectivities such as nations, peoples or states. ${ }^{44}$ Humanity's progress in history can be detected, according to Kant, in signs of history that emerge as publicly displayed attitudes of individuals, but not perforce as specific "deeds or misdeeds." ${ }^{45}$ On the basis of Tang's historical speculation, one might agree here. It seems, however, that Tang would not have hesitated to claim that certain historical events were indeed "progressive" in themselves, such as the alleged unification of China as a cultural nation, or steps taken in the global course of modernization, such as the implementation of democratic government.

Tang left open to debate the question of whether this sort of progress is reversible in the course of history. Kant, on the other hand, emphasized the irreversible impact of the public attitude with regard to the events of the French

the ideal appear as counterpart to the real, apprehends the real world in its substance, and shapes it into an intellectual kingdom. When philosophy paints its grey in grey, one form of life has become old, and by means of grey it cannot be rejuvenated, but only known. The owl of Minerva takes its flight only when the shades of night are gathering." See Hegel, Philosophy of Right, p. 20.

Tang, "Zhongguo wenhua zhi yuanshi jingshen ji suo jingli zhi tiaozhan yu you huiying er xingcheng zhi fazhan," p. 10.

The following quotations and references are from the edition of The Contest of Faculties in: Reiss, Kant: Political Writings. Tang had most likely no knowledge of Kant's text.

43 Ibid., p. 181.

44 Kant explicitly stated that he is concerned not "with any specific conception of mankind (singulorum)," but with "the whole of humanity (universorum), united in earthly society and distributed in national groups;" ibid., p. 177.

Ibid., p. 182. 
Revolution as a historical sign of progress. ${ }^{46}$ By welcoming the revolutionary founding of republican government based on a civil constitution that entailed a prohibition against wars of aggression, the public had displayed, according to Kant, a desire to participate in the implementation of these revolutionary ideas, despite the danger of suffering repression as individuals. ${ }^{47}$ Such a sign of progress would never be forgotten again, even if the revolution were to fail. Kant assumed that the lofty ideas of republican government and the abolition of wars of aggression were so closely interlaced with the general interests of humanity that such progress is historically irreversible in the long run. ${ }^{48}$

Tang did not focus, as Kant did, on the public and the attitude it displays, and he would certainly have disagreed with Kant's prediction that the progressive improvement would not be brought about by "the education of the young people in intellectual and moral culture, reinforced by the doctrines of religion." ${ }^{49}$ Kant, after all, much more than Tang, contented himself with the assumption that signs of history indicate, if nothing else, the fact that humanity's progress is at least "negatively" assured-i.e. it will unfold in the long run, ${ }^{50}$ even if there are no cultural forces present to willfully propel it.

Although the workings of reason in history and the winding course of progress may only be understood in hindsight, Tang's speculation still asserts that the realization of progress and the prevention of an ultimate catastrophe require purposeful efforts on the part of human agency. The following passage from Life, Existence and the Horizons of Mind is particularly striking in this regard:

Today it is solely true religion, morality and philosophical wisdom which are able to dominate all [kinds of] specialized knowledge and technology in order to invoke - to varying degrees and in all individuals...- - distinct moral refinement and cultivation as well as knowledge cultivated by philosophical wisdom, so as [to enable them] to embrace and tolerate each other within a vast and bright spiritual horizon. This should allow the human world to [succeed in] avert[ing] [its] collapse and disintegration,

46 In this context, Kant referred to the "attitude of the onlookers as it reveals itself in public;" ibid., p. 182.

47 Kant assumed with respect to the French Revolution that “... this revolution has aroused in the hearts and desires of all spectators... a sympathy which borders almost on enthusiasm, although the very utterance of this sympathy was fraught with danger;" ibid., p. 182.

48 Ibid., pp. 182, 185 .

49 Ibid., p. 188.

$5^{\circ} \quad$ Ibid., p. 183. 
and hence disrupt and dissolve [its] anxiety. In this case, the contemporary way to save the world consists of religion, morality and philosophy. ${ }^{51}$

In Life, Existence and the Horizons of Mind, Tang's speculation about history takes a sudden turn towards salvific thought, thereby highlighting the potency of human agency to create its own history. While the salvific assumptions clearly stand out in comparison to Tang's earlier, far more sober writings, the claim that collective normative action might create a better world had been raised by Tang time and again. The question of whether this entails a permanent salvation in terms of historical time was left unanswered. However, Tang left no doubt that any historical form of progress depends on the prerequisite that human beings attain an awareness of their role as creators of history. Tellingly, he took issue, as we have seen, with Hegel's theory of the state because he believed it insufficiently valorizes the historical force of the human will. Tang's defense of the elevated historical role of human agency also comprised a rejection of those theoreticians of historical materialism who "talked solely about historical necessity and the laws of reality as it is." ${ }^{n 2}$ In contrast, modern Confucian speculation itself was to be understood as propelling the formation of historical subjectivity (complete with a self-awareness as creators of history) and, hence, progress.

\section{Delimiting a "Philosophy of History"}

Tang had not developed a philosophy of history in the sense that he claimed to reveal either a "plan" or a "law" of history that would explain, by measure of necessity, the sequence of certain periods or epochs in history. Perhaps the case of Mou Zongsan is different. Yet for whatever reason, Mou was solely concerned with Chinese history from the Xia Dynasty (ca. 21st-16th BCE) to the Later Han Dynasty $\left(25^{-220} \mathrm{CE}\right)$ in his book on Philosophy of History (Lishi zhexue 歷史哲學) from 1955. It remains doubtful, to say the least, whether Mou's philosophy of history at all operates within the speculative mode of retracing epochal antinomies as triggers for necessary change from one period of Chinese history to the next. Equally doubtful is whether Mou Zongsan's and Tang Junyi's philosophies of history entail the teleological idea of human

\footnotetext{
51 Tang, Shengming cunzai yu xinling jingjie, Vol. 24, p. 465.

$5^{2}$ Tang in "The Genesis of Humanity" (published in Minzhu Pinglun, Vol. 3, No. 1; 1952); quoted from Huang, Xueshu yu jingshi-Tang Junyi de lishi zhexue ji qi zhongji guanhuai, p. 144 .
} 
history taking a general course towards a final goal or purpose, such as the ultimate realization of freedom and emancipation. The "ideal humanistic world" to which Tang referred would not, it seems, mark a final stage of history, nor would the forms of individual and collective freedom realized in such a society be the pinnacle of freedom. After all, the perfectibility of the human being in "inner sagehood" is not a matter of historical subjectivity. ${ }^{53}$ It rather entails a transgression of the totality of historical conditions: in realizing self-perfection in the highest form, human beings lift themselves beyond their historical existence. Accordingly, modern Confucianism does not speculate about the final realization of human emancipation in history, nor does it speculate about an apocalyptical crisis of humanity. ${ }^{54}$

European philosophies of history contain self-reflection about their own role and impact within history. This was certainly attractive for Tang as it opened a gateway to self-reflection on the pivotal role of "modernized" Confucian thought in creating historical progress: by triggering the dynamics of China's humanistic "main current," modern Confucianism would raise the historical self-awareness of the Chinese. The impulse of modern Confucianism would therefore enable China (as a cultural nation) to tap into the driving forces of history. Here, Tang was in accordance with the mainstream of European philosophies of history, which are characterized by the fact that they "see and want" progress. ${ }^{55}$

Also similar to European philosophies of history, the modern Confucian speculation about history entails both a national perspective and a vision of world history, i.e. an anticipation of modernization on a global scale. As we have seen, a crucial element of this speculation is the assumption that the process of modernization within nation-states is not self-propelled, but depends on the human factor. This accentuation of human agency and the need to attain historical subjectivity was to take the edge off a rapid social transformation that might otherwise be experienced as largely uncontrollable and contingent. What is more, modern Confucianism provided the individual

53 With respect to European philosophies of history, Marquard deems the notion of the human being's perfectibility within history to be a tenet of the historical-philosophical conception of history as the progressive development of human emancipation; see Marquard, Schwierigkeiten mit der Geschichtsphilosophie, pp. 67-68.

54 Significantly, Tang took little, if any, interest in the eschatological implications of European philosophies of history; nor did he reflect on the thesis that philosophies of history evolved out of a secularization of earlier theological speculations about history. On European philosophies of history, see Marquard, Schwierigkeiten mit der Geschichtsphilosophie, pp. 14, 67-68. 
members of society with an unchanging "anthropological" point of reference that served their need to stabilize self-images and life patterns amidst the detrimental effects of accelerated modernization. Yet there were, as we have seen, lingering contradictions between such insistence on historical subjectivity and the anthropological perspective.

In Tang's speculation, the epoch of modernity acquired a civil-theological foundation that in effect supported comprehensive and continuous modernization. One might thus speak here of a "modernizing conservativism." Such conservativism implicitly curtails criticism of modernization. This may seem odd given the abundance of critical remarks about "Western modernity" in Tang's writings. However, there is all the same a strong tendency in Tang's work to disregard any critique of modernization that is directed at fundamental structures which elude the immediate reach of interventions by human actors. This raises, in turn, the question of whether his modernizing conservativism provides individuals with a soothing, yet dubious consolation of selffulfillment, while they actually remain caught up in the "iron cage" made of modern capitalism and the bureaucratic state. This consolation, in other words, would seem illusory because the basic social, political and economic realities that cause the predicament remain unchallenged due to the deceptive immobilization of spiritually consoled individuals. If this were the case, modern Confucianism might as well function as "opium of the people." Yet one should recall that modern Confucianism neither entails the promise of an afterlife nor accepts an escapist way of life that might thoroughly placate the individual's distress under conditions of modernization. On the contrary, Tang's civil theology depicts individuals as being in constant need of addressing the modern world. Tang once even described liang zhi as the human being's "last source" of the "historical age." ${ }^{56}$ With its focus on the historical implications of liang zhi, it would seem that Tang's Confucianism may accommodate a critique of modernity that takes the increasing disempowerment of human agency into account.

56 See Tang's text from 1972: “Wang Yangming zhi liang zhi xue zhi shidai yiyi 王陽明之良 知學之時代意義” quoted from Huang, Xueshuyujingshi-TangJunyi de lishizhexue ji qi zhongji guanhuai, p. 56. In the same vein, Tang referred to the "moral self" as the driving force of human history; see Huang, ibid., p. 53 . 